\title{
The Impact of the Use of YouTube and Facebook on Students' Academic Achievement in Geography Course at the University of Jordan for the Bachelor's Degree
}

\author{
Mamon Saleem Al Zboun ${ }^{1}$, Saif Al Deen Al Ghammaz ${ }^{2}$ \& Malik Saleem Al Zboun ${ }^{1}$ \\ ${ }^{1}$ The University of Jordan, Jordan \\ ${ }^{2}$ Languages Center, University of Jordan, Jordan \\ Correspondence: Mamon Saleem Al Zboun, The University of Jordan, Jordan. E-mail: m.alzboon@yahoo.com
}

Received: January 3, 2018

doi:10.5539/mas.v12n3p164

\begin{abstract}
The aim of this study is to investigate the impact of the use of YouTube and Facebook on students' academic achievement in geography course at the University of Jordan for the bachelor's degree, and the effect of the variable of the cumulative average. The study was conducted in the first semester of the academic year 2017/2018. The study consists of two groups: the first was taught by using YouTube and Facebook and the number of its members is (43) students, and the second group which is the control group was (34) students.

A quasi-experimental approach was used and the study's tools were the educational material designed in a manner consistent with the methods of YouTube and Facebook, and a 25-point achievement test to measure the students' achievement in geography course. The validity and reliability of the study tools were verified by known scientific methods.

The results showed that there was a statistically significant effect on the achievement of the students of the University of Jordan in the geography course due to the variable of method of teaching and to the two experimental groups that were taught using the methods of YouTube and Facebook. There are too statistically significant differences $(\alpha=0.05)$ due to the cumulative average and the significance was in favor of those with good, very good and excellent assessments.
\end{abstract}

Keywords: Facebook, YouTube, achievement

\section{Introduction}

It has become possible to adopt a number of modern techniques that help in the development of educational learning process, which may assist in refining the skill of the student and teacher in accessing and using information in classrooms. Out of these modern educational techniques is the social networks such as Facebook and Twitter, Smartphone's and Internet-based communication software such as Skype and others.

The $2^{\text {nd }}$ generation Web is based on a number of key tools, including blogs, social bookmarking and social networks that are interactive and connected to a virtual medium, which is considered one of the latest technologies used in education. It is called the $2^{\text {nd }}$ generation of e-learning, it is learning via social Internet networks (Al-Masri, 2014).

The design of the social networks serves as a novel language of communication and connection amongst Internet users, relying on the techniques of the $2^{\text {nd }}$ generation Web, which overcome the barriers of space and time. Besides this, they worked to consolidate social relations between users to break the fence of social isolation in a lot of individuals, these networks are characterized by interactivity and communication in a collaborative virtual medium (Hamdi, 2010).

Social networks are seen as Internet-based web sites where millions of people share common interests. These social networks allow users to share files and pictures, create blogs, send messages,share videos and have instant conversations.

Zaidah (2012) indicated that the reason for naming these networks sites with social networks is their high potential in communicating with friends and colleagues as well as strengthening the social bonds between their 
members over the Internet. As a fact, the most eminent social networks in the world are Facebook, Twitter, WhatsApp, MySpace and others.

Types of social networking sites can be categorized into two types, namely: Closed communities as individuals communicate within a company, a university, an organization or a school, where they are invited to enter the website and participate in its activities through writing and exchanging views, files, photos and videos related to their works and tasks as well. Type 2 is a collection of social sites available to all Internet users, where many of them are allowed to participate in the various activities of the site as soon as they identify themselves to the site (Amasha, 2009).

What features the social communication networks is its appropriateness for educational uses; they provide participatory and collaborative activities among students, as well as their flexibility and easiness of use by different ages despite their rapid development (Poore, 2012). Piaget stressed that learning is built and developed through experience, that it is an active process, and a cooperative process. In light of this, the learner takes a prominent role in developing knowledge from experience, where cognitive growth comes through the interaction and participation of the individual with others and in their views concerning the lifestyle several themes and matters (Ghabari and Abu Shira, 2010).

Al-Khawalda (2010) points out that Facebook is not only a tool or a site to get to know new friends, communicate with friends, or know what is going on around the world, but also it is a great learning tool if used effectively and an important resource of information. As for teachers, they can use it in the classroom in order to improve communication, and integrate students into effective activities that differ from traditional teaching methods.

Ahmed (2010) focuses on the significance of Facebook as a social networking site that has gone viral rapidly in recent times, exceeding the geographical boundaries among people and friends, helping them communicate and exchange ideas and information and build social relations. As a matter of fact, Facebook cannot be considered merely a tool to entertain, amuse and communicate with friends, but can be considered an effective learning tool if properlyfunctioned and used. Teachers can use Facebook in the classroom to improve students' communication and participation in operative activities away from the traditional style practiced at schools.

Chapelle (2003) reported that technology has changed the teaching and learning methods of English language, as many websites offer opportunities for English language learners to converse and communicate with native speakers. The idea is that if a individual wants to learn English well, he has to go to where the native speakers live, and if the individual cannot go to an English-speaking country, he can compensate for this by signing into the chat rooms or discussion forums. She too pointed out that the considerable exposure of the individual to the language to be learned develops his ability to understand, especially the Spoken Language.

The use of social networking sites such as Facebook, Twitter, YouTube and others has spread widely throughout the world, resulting in breaking geographical boundaries and making it appear to be a small village bringing its people together. These sites have developed and become the most prevalent among Internet users; they facilitate the process of active interaction amongst the subscribers involved in providing various means of interest through various features such as instant messaging, videos, chatting, files sharing, e-mails, blogging and more (Khdar Allah, 2010; 0Karbiniski, 2010; Mwingo and Abu Darra, 2012; Charnigo and et al, 2007).

Shea and Sherer (2011) points out that many universities have established their own channels on YouTube to view their lecturing videos, and that YouTube is available for students and teachers to use effectively in and out of the classroom to help students learn, stimulate class discussions and achieve learning goals.

Trier (2007) stated that the best way to save and retain videos that an individual needs from YouTube is to create a private account on the site, which is free and easy to create, where the individual has only to go to the YouTube page on the Internet, register, and fill out some of the required key information, and then create a user name and password. Then, the individual can keep the videos in the Favorites icon on the same site, noting that this individual, who has his or her own account, can create a list of videos stored in the Favorites list to facilitate subsequent search for specific videos. According to Trier, what distinguishes YouTube is immediacy and availability; the teacher can quickly know whether the video he is in search of it is available or not.

Jones and Cutherll (2011) cited the possible uses of YouTube in the educational process, stating that YouTube videos can be used directly in the classroom as part of the teaching process. They can be used to introduce new concepts, display information during instruction, or at the end of the lesson to confirm number-one points. YouTube videos can also be used as an educational resource, where the teacher uses the video as a model for classroom activities and discussions. 
Chenail (2011) noted that the YouTube site provides students, teachers and qualitative research's experts with a unique stock of videos that illustrates the concepts of basic qualitative research, the availability of opportunities to share qualitative data through interviews and field observations and display the fully completed researches. It also provides qualitative research's researchers with the ability to view and share their own learning resources to interested people.

Abu Hamda (2016) conducted a study aimed at identifying the impact of social media on improving the writing's efficiency of ninth graders in the West Bank, Palestine. The results of the study showed that students in the ninth grade have positive attitudes towards the use of social media as one of the tools of writing in English. The results also showed that there are statistically significant differences in the effect of social media on the ninth graders to master the skill of writing in English due to the variable of qualification.

Savas (2012) conducted a study aimed at finding out the impact of video use in the teaching courses of ESL teachers for third year students at the bachelor level at a public university in Turkey, where the sample consisted of (40) male and female students. The study's results showed the usefulness of the use of videos in teaching, as it contributed to improving their skills in English as well as improving their teaching skills of English.

Batainah (2010) conducted a study aimed at finding out the impact of video use on thenon-linguistic proficiency for English language learners in universities, where the study population consisted of (760) students specialized in English language and literature at the University of Jordan. The sample of the study consisted of (35) students and the researcher identified the non-linguistic elements, namely: gestures and signs and expressions of the face and eyes. The control group was taught traditionally, while the experimental group was taught using the video, and after two months, a post-exam was conducted, where the results of the study showed that there is a difference between the control group and the experimental group in the test in favor of experimental group.

Al-Masri (2014) conducted a study aimed atidentifying the impact of Facebook on the achievement of the ninth grade students in mathematics course in Amman. The results showed that there were statistically significant differences in favor of the experimental group due to the teaching method. The results too showed that there is a statistically significant difference due to the gender of the student and in favor of females. The study also showed that there is a statistically significant difference due to the interaction between the method of teaching and gender in favor of females who were taught with the use of Facebook.

Al-Enezi (2013) conducted a study aimed at identifying the effectiveness of using Facebook on the achievement in science course and the trend towards the knowledge society of the ninth grade female students in Madinah Al-Munawarah and detecting the existence of a relationship or lack thereof between the achievement of science and the trend towards the knowledge society. The researcher found that the use of Facebook has led to an increase in students' achievement, and that there is a relationship between achievement and the trend towards the knowledge society among the ninth grade students. In light of the results of the study, the study recommended of using Facebook to teach most of the curriculum, benefitting from the group service provided by Facebook in the creation of specialized and professionalgroups, supporting the trend of female teachers towards the use of Facebook and embodyingskills preparation programs of female teachers todeal with social media.

Based on the above, the problem of the study is summarized in the search for the impact of the use of YouTube and Facebook on students' academic achievement in geography course at the University of Jordan for the bachelor's degree.

\section{The Problem \& Purpose and Questions of the Study}

The world is currently facing countless developments and changes, which may have a significant impact on society in general and on students in particular. One of the most significant developments in the world of the Internet is the social networks including Facebook, Twitter and others. Social media sites (Facebook and YouTube) are considered the new technologies that help in the development of educational learning process, as it is experiencing a dynamic movement of development and spread, where Facebook has been successful since its inception. Though these websites were established primarily for social networking between individuals, the use of Facebook and YouTube extended to the educational processby developing educational programs and activities for students in order to take advantage of the student's time and develop his personality; the educational process is not only teaching a lesson, but also an educational and active process with clear objectives aimingat building the personality of the student in all respects. More tellingly, the educational process tries to find an integrated balance among all traits of his personality, as it helps in refining the skills of students and teachers to access and share information in classrooms to improve communication and integrate students into effective activities.

Students are currently suffering from a lack of learning in geography course and its skills due to the 
overcrowding of students in classes, the lack of time to perform enrichment and therapeutic activities, the traditional methods of teaching that do not take into account the needs of students, their interests, their tendencies and their desires as well as the absence of technology, the lack of classes for educational tools and the highly required skills. Accordingly, all of this led to weakness in the student's achievement and their importance to the individual at the academic level as a tool for acquiring knowledge and at the social level as a means of communicating with others.

In their (2015) study, Hussein and Ghoul pointed to the impact of using Facebook method on the achievement of ninth grade students in English language and the impact of the cumulative average on this and the interaction between them. They also clarified that the achievement of ninth grade students in English language has increased using Facebook compared to the traditional method.

There was a bad need for educational strategies to keep up with the contemporary times, along with teaching methods that develop students' confidence in their skills and abilities in learning geography and try to overcome the traditional ways of bridging the gap between the requirements of the current age and the students' aspirations. Therefore, the problem of the study has crystallized the answers to the following questions:

1. Does the academic achievementof the students of the University of Jordan at the bachelor's degree differ in geography according to the method of teaching (YouTube, Facebook or the traditional method?

2. Does the academic achievementof the students of the University of Jordan at the bachelor's degree differ in geography according to the student's cumulative average (excellent, very good, good or acceptable?

At last, the study aimed at finding out the impact of the use of YouTube and Facebook on students' academic achievement in geography course at the University of Jordan for the bachelor's degree compared to the traditional method and the impact of the cumulative average.

\section{The Importance of Study}

The subject of this study is significant from both theoretical and practical aspects:

- Consistent with the instructions of the Ministry of Higher Education in Jordan to introduce the idea of e-learning in teaching courses to suit technological development.

-Raising awareness of YouTube and Facebook as one of the sources of electronic educational videos that serve the educational learning process.

-Using a contemporary method of education that enhances students' self-learning and interaction with the curriculum electronically.

Owing to the lack of studies on the significance of both YouTube and Facebook according to the researchers, this study confirms the importance of keeping up with the scientific and electronic progress in raising the level and efficiency of students in the geography course of students of the University of Jordan, which contributes to the development of methods and approaches of education among students through the modern and developed strategies provided by the teachers.

The current study is expected to open venues for other studies to address the impact of the use of social media sites on student's achievement and motivation towards learning, and the impact of these websites on the process of effective teaching and the possibility of its activation and application too.

\section{The Tools, Scope and Limitations of Research}

The study is subject to the following limits:

Spatial limitations: The study was applied to the students of the University of Jordan for the bachelor's degree.

Time Limitations: This study was applied in the first semester of the academic year 2017/2018.

Human Limitations: Students of the University of Jordan for the bachelor's degree.

Objective Limitations: The study was limited to the first unit in the geography course'stextbook for the students of the University of Jordan for the bachelor's degree in Jordan. The textbook will include educational videos, electronic learning games, activities, assignments and electronic tests designed for Microsoft Office programs and others.

The study relied on the use of tools prepared by the researchers to measure the impact of using YouTube and Facebook on the academic achievement of the students of the University of Jordan in geography course. 


\section{The Study's Definitions}

1. Facebook: A social media network available on the Internet, through which information, feelings and ideas are sharedamong people (Al-Masri, 2014).

Procedural Definition: The use of Facebook in the teaching of geography course is practiced so as to present the educational material through the formation of a closed group of students to view the required tasks, and the dissemination of various files, namely: educational images and videos, PowerPoint slides and useful links, where students see the educational task, read, understand and discuss it among them. Facebook is also used to broadcast significant events, receive and submit of school assignments and ensure the achievement of educational objectives through electronic tests that the faculty member publishes on Facebook.

2. YouTube: A website that allows its users to upload, watch, share, comment on and view live video recordings for free.

Procedural Definition: A website that contains all the geography course videos that help students acquire any skills related to the content of the curriculum, where students can download, watch and share videos related to the subject of the module.

3. Academic Achievement: What the learner acquires such as skills, knowledge and different sciences, as a result of a variety of learning processes that indicate his cognitive mental activity and is measured by the degree he achieves in a standardized exam when he is asked to do so (Al-Jalali, 2011).

Procedural Definition: The amount of experiences, knowledge, information and concepts acquired by the learner on the content of the scientific course and measured by the total scores obtained by the learner in the test prepared for this purpose.

\section{The Study's Methodology and Procedures}

\subsection{The Study Approach}

The study used the quasi-experimental method to identify the impactof using YouTube and Facebook on the achievement of the students of the University of Jordan for the bachelor's degree in geography course compared to the traditional method in addition to the effect of the cumulative average on this and the interaction between them, considering that this approach is the most appropriate for the objectives and questions of the study.

\subsection{The Study's Sample}

The sample members were selected purposely to provide the required capabilities for this study from the male and female students of the University of Jordan for the bachelor's degree. The groups were randomly selected, where the number of students was 77 students, divided into two groups: the first group with 43 students taught by using YouTube and Facebook, and the second group with 34 students taughtby using the traditional method.

Table (1) shows the distribution of students according to the teaching strategy and the cumulative average.

Table 1. Frequency and percentages by method of study and study variables

\begin{tabular}{lll}
\hline Categories & Frequency & Percentage \\
\hline Group & YouTube and Facebook & Group 43 55.8 \\
Traditional & Method & 3444.2 \\
Cumulative & Average acceptable & 3545.5 \\
Good & & 1418.2 \\
Very Good & & 1519.5 \\
Excellence & 1316.9 \\
\hline
\end{tabular}

\subsection{The Study's Tools}

The aim of this study was to identify the impact of using YouTube and Facebook on the academic achievement of the students of the University of Jordan for the bachelor's degree in geography course compared to the traditional method and the effect of the cumulative average. To achieve these goals, the researchers developed 
the following tools:

\subsubsection{First: Educational Material Designed in Facebook and YouTube.}

The first unit of geography textbook for bachelor's degree at the University of Jordan for the first semester (2017/2018) was selected for its relevance to the study's objectives, methodology and educational activities proposed by the researchers.

The behavioral objectives were prepared and formulated along with preparing a material which matches the use of YouTube and Facebook in teaching. The material included the educational objectives, content, teaching strategies, sources of learning and teaching aids and assessment, as it was formulated to be 12 teaching hours over 4 weeks. The educational material has been developed in accordance with the proposed educational activities of Facebook and YouTube with being committed to the course content. Instructing activities for teaching the unit were conducted using YouTube and Facebook, including educational videos designed through powerdirector software, moviemaker software, educational videos through YouTube, images, written texts and worksheets as they have an active role in enriching learning. Various Power Point slides were also presented to show the material in an exciting and interesting manner designed in a way that fits with the content of the unit and all designed in a manner that adds fun, action, thrill and amusement, and all were posted on the YouTube and Facebook pages to suit the content of the subject.

\subsection{The Educational Material's Validity and Reliability}

The reliability of the educational material has been verified by presenting it with all of its educational activities on (15) specialized experts in the field of education and information technology, methods of teaching, geography, measurement and evaluation in the following universities: University of Jordan, Hashemite University and Yarmouk University. The material was amended in accordance with the observations of $80 \%$ of the experts, where each expert was provided with a copy of the designed material and was asked to express an opinion on the clarity, accuracy and sequence of the educational material, appropriate use of sounds and colors, background suitability and appropriateness of the lines, as well as the adequacy and integrity of the linguistic content. Based on the observations of the experts, which were all centered on the sequence of the teaching material, the consistency of colors and language formulation, these materials have been amended and developed until they reached the final form. The study was conducted on an exploratory sample outside the sample of the study, which consisted of (12) students from the University of Jordan for three weeks, where the suitability of the educational material for the study was confirmed, and students were asked about the difficulties encountered in the educational material or things that they did not understand. As for the sample, the sample showed that the material is interesting, easy and understandable, and therefore, the educational material is ready to be applied in the final form.

\subsubsection{Second: The Academic Achievement Test}

In order to achieve the objectives of the study, a study test was constructed consisting of (25) objective questions of the type of multiple choice, prepared according to the specifications of the unit of geography of Jordan for the first semester (2017/2018), so that students choose the correct answer to the question from four choices whose one of them is true. The test allocated (25) points per unit, and each paragraph a grade according to the grades assigned in the specifications table. The students' academic achievement in geography course can be inferred through the total mark they take in the achievement test in the unit of geography of Jordan in their course.

\section{The Test's Validity}

In order to verify the validity of the test, it was presented in its initial form to a group of 15 experts who are specialized in curriculum and teaching, teaching methods, geography, measurement andassessment and educational technology, and amended according to the observations of $80 \%$ of the experts. To ensure the reliability of the test, the method of testing and retesting was applied so that it was applied in the final form to apilot sample of 12 students from the University of Jordan for the bachelor degree who studied the unit of geography of Jordan outside the sample of the study. These studentsshare the same characteristics of the sample of the study as the circumstances, possibilities and facilities provided.

\section{The Test's Reliability}

To verify the reliability of the test according to the reliability coefficient for the academic achievement test, it has been found equal to (79.), and the reliability coefficient value is acceptable for study purposes. According to the difficulty and discrimination coefficient of the test paragraphs, the difficulty coefficients on most test paragraphs were appropriate $(0.33-0.83)$. These percentages are considered acceptable for study purposes as some paragraphs were amended and the inappropriate paragraphs were deleted as well. As for the discrimination 
coefficient of the paragraphs, they ranged from (.30) to (.60), where the paragraphs are generally distinct, in an acceptable sense for the purposes of study. Weak paragraphshave been modified in terms of discrimination too. According to the coefficient of internal reliability using the Cronbach's alpha Formula, its value was (.80) and is acceptable for the purposes of study.

\section{The Study's Variables}

The study included a number of variables, namely:

A. Independent Variable: 1-It includes the method of teaching as well as two levels:

Teaching can be done through: A - YouTube and Facebook B - The Traditional Way.

2. Cumulative Average with four levels: A- Excellent B- Very Good C- Good D- Acceptable.

B. Dependent Variables: are the averages of students' academic achievement in the post-test.

Study's Design

EG1: O X1 O

CG1: O O

Where:

EG: Experimental Group.

EG1: A group that will be taught using YouTube and Facebook.

CG: Control Group that will be taught in the traditional way.

$\mathrm{O}$ : Achievement test (pre-test and post-test).

$\mathrm{X} 1$ : Processing using Facebook and YouTube.

\section{Statistical Processing}

In order to answer the study questions, the study adopted the appropriate statistical methods obtained from data analysis, the use of descriptive and indicative statistical methods of Arithmetic mean and standard deviation, and the use of the ANCOVA analysis to adjust the pre-differences from the measurement of the study variables and to find the difference between the average of performance of experimental groupsand control groups in the post-test of academic achievement.

\section{The Study's Results and Discussion}

Second: Results related to the first question

Question 1: Does the academic achievement of students of the University of Jordan differ for the bachelor's degree in geography course according to the method of teaching (YouTube, Facebook and the traditional way?

In order to answer this question, the Arithmetic means, standard deviations and modified averages were obtained for the academic achievement of the students of the University of Jordan for the bachelor's degree in geography course according to the variable of teaching method (YouTube, Facebook and the traditional method). Table (2) shows this.

Table 2. Arithmetical means and pre and post standard deviations of the experimental and control group

\begin{tabular}{llllll}
\hline \multirow{2}{*}{ Group } & Number & Pre-test & \multicolumn{3}{c}{ Post-test } \\
\cline { 3 - 6 } & & AM & SD & AM & SD \\
\hline Experimental & 43 & 0.09 & 0.71 & 19.85 & 0.36 \\
\hline Control & 34 & 0.46 & 0.63 & 13.72 & 3.46 \\
\hline
\end{tabular}

Table (2) shows that there are apparent differences between the average of performance of the experimental and control groups in the achievement test. To determine whether these differences are statistically significant at the level of $\alpha=0.05$, ANCOVA was performed as shown in Table (3). 
Table 3. ANCOVA analysis of the effect of the teaching method on post-achievement

\begin{tabular}{cccccc}
\hline Source of Variance & Total of Squares & Degrees ofFreedom & Mean ofSquares & Value F & Level of Significance \\
\hline Common pre-achievement & 1 & $\mathbf{7 . 0 2 0}$ & 966 & .321 \\
\hline Group & 1 & $\mathbf{9 0 4 . 3 2 0}$ & 128.29 & $.000^{*}$ \\
\hline Error & 75 & $\mathbf{6 6 9 . 6 1 1}$ & & \\
\hline Total & 76 & $\mathbf{1 5 7 4 . 0 0 0}$ & & \\
\hline
\end{tabular}

*Statisticalsignificance at level $(\alpha=0.05)$

Table (3) shows statistically significant differences in the post-achievement of students between the control and experimental groups where the value of (F) was 128.29. This value is statistically significant at the level of significance $(\alpha 0.05=)$ after the differences were statistically determined in the pre-test by using (ANCOVA). The differences were in favor of the experimental group where the experimental arithmetic mean of the experimental group was (19.85) and the control group was (13.72).

It is clear from the above that there is a significant impact on the academic achievement of the geography course on the students of the University of Jordan due to the variable of method of teaching for the experimental group taught by using YouTube and Facebook, and that the average of scores of the experimental group students taughtby using YouTube and Facebook exceeds the average of scores of students of the control group taughtby using the traditional method. This indicates the effectiveness of the use of both YouTube and Facebook in the process of teaching of geography course to the students of the University of Jordan.

More tellingly, it sounds that the method of YouTube and Facebook, including the class interaction with all its sortssuch as the voice and image and the movement of social communication has increased the motivation of students and strengthened the concepts and content of students. The reason may be that the students learned in a way they have not experinced before, allowing them to read and review the material more than once and at any time. Moreover, this current method enhanced their knowledge of the educational material and contributed to the development of learning in an interesting and attractiveway, especially as they deal daily with the channels of social communication.

The results also showed that there was a significant impact on the academic achievement of the geography courseon the students of the University of Jordan due to the variable of method of teaching for the experimental group that was taught using YouTube. This result is consistent with a number of previous studies that indicated that teaching using YouTube has a positive impact on students' learning in general and in particluar academic achievement, such as Eick and King (2012) and Tan and Pearce (2011), who pointed to the importance of using educational videos because of their impact on increasing student's achievement in various subjects, both school and university.

This finding is attributed to the fact that learning through YouTube has become one of the basic learning resources in the student's life at the present time, for it provides illustrations, growth of knowledge and easiness of searching for sources of knowledge. It too gives students limitless space for self-learning and knowledge acquisition as desired by the student, as opposed to other learning sources in which knowledge is defined with narrower boundaries. It can also contribute to the development of students' learning with all its different skills, by helping the learner plan to learn, set goals, determine and mange time and decide the appropriate place to learn. This finding is consistent with the results of the Eck and King study (Eick and King, 2012).

It is possible that the current result is attributed to the advantages enjoyed by Facebook, which are expected to serve students' learning and contribute to improve their educational level. Out of these advantages is that this type of learning enables the learner to review and study his educational material more than a once without feeling bored at the time he wants and where he wants and this in general increases the motivation to learn, which increases the direct academic achievement. The method of learning through Facebook is a noveltechnique for students, which has raised their interest and increased their motivation to learn as this is confirmed by the results of previous studies such as the 2014 study of Hussein and AL Ghoul and the 2014 study of Al-Masri.

\subsection{Third: Results Related to the Second Question}

Question 2: Does the academic achievement of students of the University of Jordan differ in the undergraduate level in geography course according to the student's cumulative average, namely: excellent, very good, good or acceptable?

In order to answer this question, the Arthimitic means and standard deviations were obtained for the academic 
achievement of the students of the University of Jordan for the bachelor's degree in geography course according to the student's cumulative average, namely: excellent, very good, good, acceptable?And the table below illustrates this:

Table (4). Arthimitic means and standard deviations of the academic achievement of the students of the University of Jordan for the bachelor's degree in geography course according to the variable of cumulative average of the student

\begin{tabular}{llll}
\hline Categories & The number & Arthimitic Mean & Standard Deviation \\
\hline Accepted & 35 & 12.53 & 3.909 \\
\hline Good & 14 & 17.00 & 3.234 \\
\hline Very good & 15 & 18.00 & 4.592 \\
\hline Excellent & 13 & 19.69 & 3.093 \\
\hline Total & 77 & 15.40 & 4.755 \\
\hline
\end{tabular}

Table (4) shows an apparent difference in the Arithmetic averages and standard deviations of the University of Jordan students' academic achievement for the bachelor's degree in geography course because of the difference of categories of the variable of the cumulative average of the student (excellent, very good, good or acceptable). To illustrate the significance of the statistical differences between the arithmetic averages, a single variance analysis was used according to Table (5).

Table (5). Analysis of the single variance of the effect of the cumulative average of the student on the academic achievement of the students of the University of Jordan for the bachelor's degree in geography course

\begin{tabular}{|c|c|c|c|c|c|c|}
\hline The Source & $\begin{array}{l}\text { Total number of } \\
\text { Squares }\end{array}$ & $\begin{array}{l}\text { Degrees } \\
\text { Freedom }\end{array}$ & of & $\begin{array}{l}\text { The mean of } \\
\text { Squares }\end{array}$ & Value $\mathrm{P}$ & $\begin{array}{l}\text { Statistical } \\
\text { Significance }\end{array}$ \\
\hline Among groups & 670.277 & 3 & & 223.426 & 15.559 & .000 \\
\hline Within groups & 1048.243 & 73 & & 14.359 & & \\
\hline The total & 1718.519 & 76 & & & & \\
\hline
\end{tabular}

Table (5) shows that there are statistically significant differences at the level of significance $(\alpha=0.05)$ due to the cumulative average on the academic achievement of the students of the University of Jordan for the Bachelor's degree in geography course. In order to show the statistically significant differences between the arithmetic means,Least Significant Difference (LSD) post-comparisons were used as shown in Table (6).

Table (6). LSD post-comparisons of the effect of the cumulativeaverageof the student on the academic achievement of the students of the University of Jordan for the bachelor's degree in geography

\begin{tabular}{|c|c|c|c|c|c|}
\hline & $\begin{array}{l}\text { Arithmetic } \\
\text { Average }\end{array}$ & Acceptable & Good & Very Good & Excellent \\
\hline Acceptable & 14.50 & & & & \\
\hline Good & 18.09 & $4.47^{*}$ & & & \\
\hline Very Good & 19.50 & $5.47 *$ & 1.00 & & \\
\hline Excellent & 21.63 & $7.17^{*}$ & 2.69 & 1.69 & \\
\hline
\end{tabular}

*Significance at level $(\alpha=0.05)$

Table (6) shows the following:

There are statistical significant differences of $(\alpha=0.05)$ between the acceptable on the one hand and all of the good, and very good and excellent on the other hand, and the differences were in favor of both good, and very 
good and excellent.

This aforementioned result may be a normal result because those who have high averages are more willing and tend, dependingon their academic achievement and their high abilities, to learn using technological innovations such as YouTube and Facebook. The method of YouTube and Facebook, including videos, software, activities, assignments, electronic tests and immediate feedback, and communicating with the teacher and colleagues make high-average students tend to accept to learn in this way as it increases their motivation and activity as well as their desire to learn. This method also opensnew venues of science and knowledge in geography course for students in a way making them superior to their colleagues who have an acceptable average and with a statistically significant difference, who were, by virtue of their averages, less motivated and inclined to learn in this way. More importantly, this applies to students with good, very good and excellent cumulative averages due to their high abilities to excel in terms of statistics, noting that this result is consistent with the results of the study (Hussein and Al-Ghoul, 2014).

\section{Conclusions}

- There is a significant impact on the academic achievement for the geography course of the students of the University of Jordan due to the variable of method of teaching, in favor of the experimental group taught by using YouTube and Facebook. This refers to the impact of the use of YouTube and Facebook in the teaching of geography course to the students of the University of Jordan.

- There are statistically significantdifferences between the students with acceptable average on the one hand and all of the good, very good, and excellent on the other hand, and the differences were in favor of both good, and very good, and excellent, and attributed to the teaching method, in favor of the experimental group taught by using YouTube and Facebook. This refers to the impact of using YouTube and Facebook.

- There are statistically significantdifferences between the level of high experience on the one hand and each of the low and medium experiences on the other hand and the differences were in favor of the level of high experience due to the teaching method, and for the benefit of the experimental group taught by using YouTube and Facebook. This refers to the impact of using YouTube and Facebook.

\section{Recommendations}

In light of the results of the study, the researcher recommends the following:

1. Activating YouTube and Facebook in teaching geography course because of their effectiveness in education.

2. Paying attention to students of low and medium averages to raise their academic and technological level and take advantage of the potentials of YouTube and Facebook in their education.

\section{References}

Abu Hamda, E. (2016). The Impact of Social Communication and Improving the Literary Efficiency of Grade 9 Students in the West Bank, Master Thesis, An-Najah National University, Nablus, Palestine.

Ahmed, Y. (2010). Using the Facebook social network in education. Retrieved from http://docs.com/COD6

Amasha, M. (2009). E-learning and social networking services. Journal of Informatics, (27), 24-30. Retrieved from http://informatics.gov.sa/details.php?id=313

Anzi, J. (2013). Effectiveness of the use of social networks in the collection of science and the trend towards the knowledge society of the third grade students in Medina. PhD Thesis, Umm Al Qura University, Kingdom of Saudi Arabia.

Bataineh, A. (2010). The Effect of Using Videos on University EFL Learners' Nonverbal Competence. Journal of IslamicUniversity, (2), 1295-1322 .

Chapelle, C. (2011). English Language Learning and Technology, 1stEd., (2003), John Benjamins Publishing Co., Philadelphia - USA.

Chenail, R. (N/A). YouTube as a Qualitative Research Asset: Reviewing User Generated Videos as Learning Resources. The QualitativeReport, (1), 229-235.

Egyptian, A. (2014). The Effect of Facebook on the Achievement of Ninth Grade Students in Mathematics, Master Thesis, Hashemite University, Zarqa, Jordan.

Eick, C., \& King, D. (2012). Nonscience Majors' Perceptions on the Use of You Tube Video to Support Learning in an Integrated Science Lecture. Journal of College Science Teaching, 42(1), 26-30. 
Galali, G. (2011). Educational achievement, Dar Al-Masirah, 1, Amman.

Hamdi, R. (2010). Social Networking Risks. Journal of e-Learning. Retrieved from http://emag.mans.edu.eg/index.php?sessionID $=17$

Hsu, W. (2011). YouTube in an EFL Compassion Class. Arab WorldEnglish Journal (AWEJ), (2), 91-132.

Hussein, J., \& Aynas, G. (2014). The effectiveness of using Facebook in the achievement of the English language in the ninth grade students, research under publication.

Ibrahim, M. (2013). The Impact of Using Facebook on Developing Written Performance in English for Ninth Grade Students, Master Thesis, An - Najah National University, Nablus, Palestine.

Jarrett, K. (2010). YouTube: Online Video and Participatory Culture, Continuum. Journal of Media \& Cultural Studies, 24(2), 327-330.

Jones, T., \& Cuthrell, K. (2011). YouTube: Educational Potentials and Pitfalls, Computers in the Schools, 75-85.

Khawaldeh, A. (2010). Facebook in Education, Retrieval from: http://www.islamic-ec.edu.jo/ Education. Aspx \# a47.

Mekheimer, M. (2011). The Impact of Using Videos on Whole LanguageLearning in EFL Context. Arab World English Journal (AWEJ), 2, 25-39.

Ministry of Education, Jordan (2006). Teacher's Guide.

Savas, P. (2012). Micro-teaching Videos in EFL Teacher Education Methodology Courses: Tools to Enhance English Proficiency and Teachers Skills among Trainees, Procedia - Social and Behavioral Sciences, 55, 730-738.

Wang, J., Chun-Fu, C., Lin, W., \& Emily, W. (2013). Meaningful engagement in face book learning environments: Merging social \& academic lives. Turkish On line Journal of Distance Education, 1, Art. 26 .

Yang, C., Hsu, Y., \& Tan, S. (2010). Predicting the Determinants of Users' Intentions for Using YouTube to Share Videos. Moderating Gender Effects, Cyperpsychology, Behavior, and Social Networking, (2), 141-152.

Zaidieh, A, (2012). The Use of Social Networking in Education: Challenges and Opportunities. World of Computer Science and Information Technology Journal, (1), 18 -21.

\section{Copyrights}

Copyright for this article is retained by the author(s), with first publication rights granted to the journal.

This is an open-access article distributed under the terms and conditions of the Creative Commons Attribution license (http://creativecommons.org/licenses/by/4.0/). 